\title{
MINERALIZAÇÃO E DESNITRIFICAÇÃO DO NITROGÊNIO NO SOLO SOB SISTEMA PLANTIO DIRETO ${ }^{(1)}$
}

\author{
MARCOS SIQUEIRA NETO $\left({ }^{2 *}\right)$; MARISA DE CÁSSIA PICCOLO $\left({ }^{2}\right)$; \\ SOLISMAR DE PAIVA VENZKE FILHO (3); BRIGITTE JOSEFINE FEIGL $\left({ }^{2}\right)$; \\ CARLOS CLEMENTE CERRI $\left({ }^{2}\right)$
}

\begin{abstract}
RESUMO
O conhecimento da dinâmica do $\mathrm{N}$ no solo pode facilitar na decisão da rotação de culturas empregada e aplicação de fertilizante para as culturas. O objetivo deste estudo foi avaliar os estoques de $\mathrm{N}$, o N-inorgânico, a mineralização do $\mathrm{N}$ e a desnitrificação sob sistema plantio direto (SPD). O experimento foi desenvolvido na Fazenda Santa Branca em Tibagi (PR), em Latossolo Vermelho distroférrico de textura argilosa, no período de setembro de 2000 a outubro de 2001. Os tratamentos dispostos em faixas não casualisadas com parcelas subdivididas foram: plantio direto por 12 e 22 anos com as sucessões milho/trigo (M/T) e soja/trigo (S/T). As quantidades de $\mathrm{N}$-inorgânico e a mineralização e nitrificação líquidas foram maiores no SPD com 22 anos que no SPD 12 anos. A sucessão de culturas empregada não influenciou a mineralização líquida e a nitrificação líquida. As emissões de $\mathrm{N}_{2} \mathrm{O}$ foram $25 \%$ superiores na sucessão M/T em relação a S/T. O tempo de SPD aumentou o estoque de $\mathrm{N}$ no solo, assim como as quantidades de $\mathrm{N}$-inorgânico e a mineralização e nitrificação, contudo, não foram observados maiores emissões de óxido nitroso.
\end{abstract}

Palavras-chave: estoques de $\mathrm{N}$ no solo, $\mathrm{N}$-inorgânico, Nitrificação, $\mathrm{N}_{2} \mathrm{O}$.

\section{ABSTRACT \\ MINERALIZATION AND DENITRIFICATION OF SOIL NITROGEN UNDER NO-TILLAGE SYSTEM}

The knowledge of $\mathrm{N}$ dynamics in soil can facilitate the decision about crop rotation and the fertilizer application to the crops. The objective of this study was to quantify the soil N-stocks, inorganic- $\mathrm{N}$ and changes in the net mineralization and denitrification in a soil under no-tillage (NT). The experiment was set up at Santa Branca Farm in Tibagi (Paraná State, Brazil), on a clayey Oxisoil (Typic Hapludox) and was carried out from September 2000 to October 2001. The treatments were applied in non-random strips with split plots: no-tillage during 12 and 22 years with corn/wheat and soybean/wheat succession. Quantity of inorganic-N and the net mineralization and nitrification were higher under 22-years of adoption in relation to the 12-year-old NT. The crop succession used did not affect the average net mineralization and net nitrification. The $\mathrm{N}_{2} \mathrm{O}$ emissions were $25 \%$ higher in corn/wheat crop succession in relation to the soybean/wheat. Increasing time of no-tillage adoption increased the soil N stock, inorganic-N and net mineralization in the soil, but the different years of adoption of NT did not lead to changes in $\mathrm{N}_{2} \mathrm{O}$ emissions.

Key words: soil $\mathrm{N}$ stocks, soil inorganic N, Net nitrification, $\mathrm{N}_{2} \mathrm{O}$.

(1) Recebido para publicação em 18 de março de 2008. Aceito em 10 de maio de 2010.

(2) Centro de Energia Nuclear na Agricultura, Universidade de São Paulo, Caixa Postal 96, 13400-970 Piracicaba (SP), Brasil. E-mail: msiqueir@gmail.com ( ${ }^{*}$ ) Autor correspondente.

(3) Rotar - Crop prodution System. E-mail: contato@rotar.com.br 


\section{INTRODUÇÃO}

O preparo do solo nos países de clima temperado tem como principal objetivo a interrupção do ciclo entre o inverno e a primavera. Porém, em solos de clima tropical, a fertilidade natural é limitada, e o revolvimento das camadas superficiais intensifica os processos de oxidação do material orgânico (DENARDIN e KochHANN, 1993). O sistema plantio direto (SPD) com a manutenção dos resíduos culturais oferece proteção ao solo, e proporciona o aumento da matéria orgânica do solo (MOS) (SÁ et al., 2001), com alterações nas condições químicas (FALLEIRO et al., 2003), físicas (TORMENA et al., 2004) e biológicas do solo (Peres et al., 2005).

A quantidade total de nitrogênio no solo está entre 0,05\% e 0,5\%, ligado a inúmeros compostos orgânicos, sendo, geralmente, menos de $5 \%$ do elemento nas formas inorgânicas como amônio e nitrato (WHIETHÖLTER, 2000).

Nos sistemas agrícolas as fontes de $\mathrm{N}$ são: a deposição atmosférica (CARvAlHo JUNIOR, 2004), a fertilização nitrogenada, a fixação biológica do $\mathrm{N}_{2}$ atmosférico (SCHLESINGER, 1997) e a mineralização do N-orgânico do solo (Bustamante et al., 2004).

$\mathrm{O} \mathrm{N}$ disponível para as plantas depende, entre outros fatores, da quantidade de MOS no solo (AMADO et al., 2001), da característica dos resíduos vegetais (Trinsoutrot et al., 2000), do manejo adotado (KRISTENSEN et al., 2003), do tipo de solo (THOMSEN et al., 2000), da umidade, da aeração e da temperatura do solo (SIERRA e MARBÁN, 2000).

A concentração de $\mathrm{N}$ assim como a composição bioquímica dos resíduos culturais são fatores determinantes para a mineralização ou imobilização do elemento no solo (GLASENER et al., 2002, MARQuEZ et al., 2000, MARY et al., 1996). A utilização de leguminosas em sistemas de rotação de culturas é uma estratégia que deve ser considerada quanto ao seu efeito no aumento do N no solo (DieKow et al., 2005, Lovato et al., 2004, SISTI et al. 2004), como também na substituição parcial do $\mathrm{N}$-fertilizante pelo $\mathrm{N}$-fixado simbioticamente, que resulta na liberação gradativa do elemento e na redução da emissão de $\mathrm{N}_{2} \mathrm{O}$ (AMADO et al., 2001).

A aplicação do N-fertilizante depende do entendimento da dinâmica do elemento no solo. Diversos autores (Touchton e Hargrove, 1982, Rice e SMith, 1984, PÖtTKer e Roman, 1994, LARA CABEZAS, 2001) afirmaram que a utilização de uréia no SPD não é uma fonte eficiente de $\mathrm{N}$ para o sistema devido a perdas por volatilização e, com o acúmulo de resíduos culturais em superfície com elevada relação C:N, favorece a imobilização do $N$ pelos microrganismos do solo (CARPENTER-BOGGS et al., 2000).

A produção de óxido nitroso $\left(\mathrm{N}_{2} \mathrm{O}\right)$ no solo está relacionada com a disponibilidade de $\mathrm{N}$ (WeIrz et al.,
2001). Em solos em condições favoráveis de umidade, a emissão do óxido nitroso pode chegar a 1,25\% do $\mathrm{N}$-fertilizante aplicado (DALAL et al., 2003). Esta emissão pode parecer baixa comparada com a entrada de $\mathrm{N}$ no sistema, contudo para o ambiente essa quantidade pode ser elevada se considerar que o potencial de aquecimento global do $\mathrm{N}_{2} \mathrm{O}$ é de aproximadamente 300 vezes maior que o $\mathrm{CO}_{2}$ (IPCC, 2001).

A quantidade de $\mathrm{N}$ que recicla em um sistema normalmente está entre 10 e 20 vezes maior que a quantidade recebida por fontes externas (SCHLESINGER, 1997). O conhecimento da dinâmica do $\mathrm{N}$ nos sistemas agrícolas é importante para garantir o sincronismo entre o suprimento de $\mathrm{N}$ no período de demanda das culturas, a fim de evitar perdas com prejuízos econômicos e ambientais. Assim, o objetivo deste estudo foi avaliar o efeito do tempo de implantação do SPD com duas sucessões de culturas nas alterações das quantidades de N-total e inorgânico e, nas taxas líquidas de mineralização e desnitrificação do $\mathrm{N}$ no solo.

\section{MATERIAL E MÉTODOS}

O experimento de campo foi instalado a $24^{\circ} 36^{\prime} \mathrm{S}$ e $50^{\circ} 23^{\prime} \mathrm{O}$, no município de Tibagi (PR). O solo sob vegetação nativa foi classificado como um Latossolo Vermelho distroférrico de textura argilosa (EMBRAPA, 2006). O clima da região é Cfb (KöPPEN-GeIGer), clima temperado oceânico quente sem ocorrência de estação seca definida, com verões frescos (temperatura média abaixo de $20^{\circ} \mathrm{C}$ ) e geadas no inverno. A precipitação pluvial e a temperatura média anual são de $1.600 \mathrm{~mm}$ e $19^{\circ} \mathrm{C}$ respectivamente (Figura 1 ).

A área estudada permaneceu sob vegetação nativa até 1969 , quando foi convertida em agricultura. A área foi cultivada com arroz de sequeiro (Oriza sativa L.) por três anos sob preparo convencional. Em seguida foi adotada a sucessão de soja (Glicine max. L. Merril) no verão e trigo (Triticum aestivum L.) no inverno por sete anos. Em 1979, 30\% da área foi convertida em plantio direto (área com 22 anos), adotando-se a rotação de cultura com soja e milho (Zea mays L.) no verão e trigo e aveia preta (Avena strigosa, Schreb) no inverno. Em 1989, no restante da área, que havia permanecido sob pousio, adotou-se o sistema plantio direto (12 anos). De 1979 a 2001 (22 anos), foram cultivados dezesseis ciclos de soja e seis de milho no verão, enquanto no inverno foram doze de aveia preta intercalados com sete ciclos de trigo. No período de 1989 a 2001 (12 anos), foram cultivados sete ciclos de soja intercalados com cinco de milho no verão, enquanto no inverno foram seis de aveia preta intercalados com cinco ciclos de trigo (SÁ et al., 2001).

O experimento teve início em setembro de 2000 com a demarcação das áreas. As áreas experimentais 


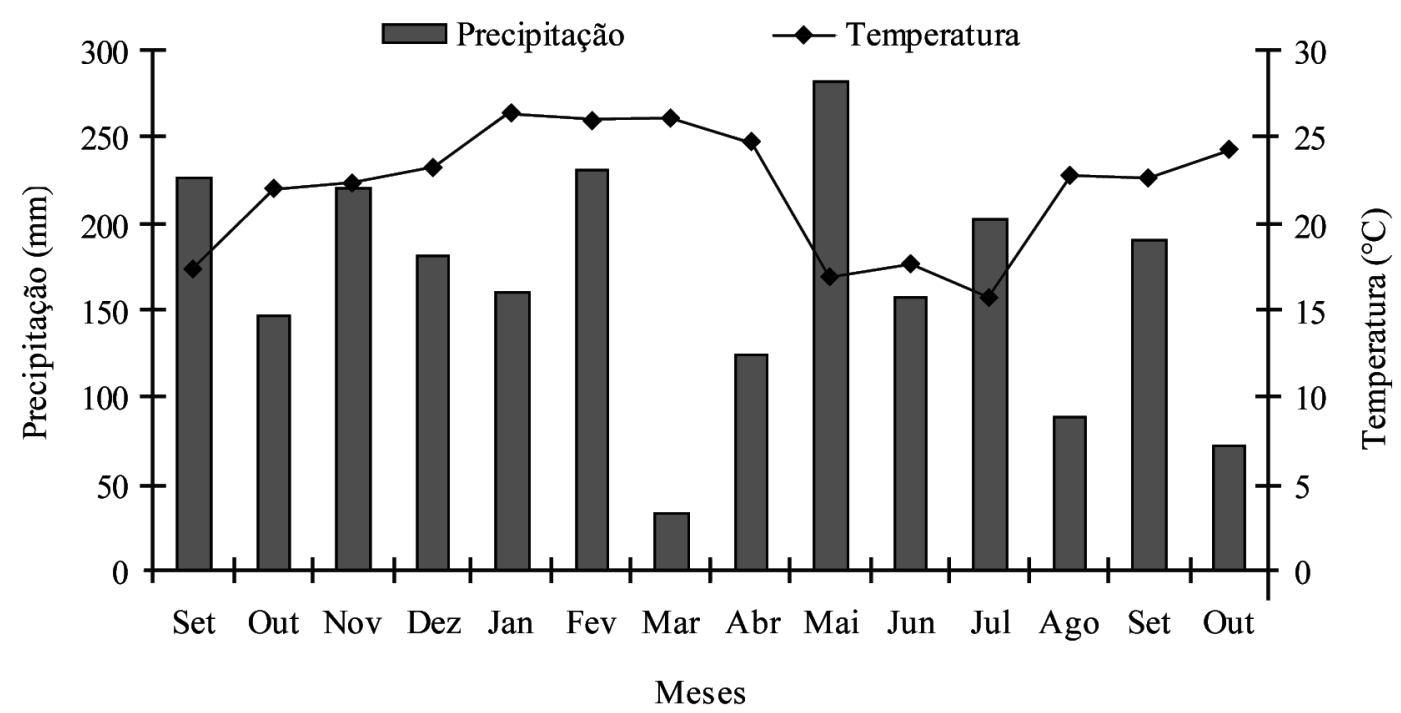

Figura 1. Precipitação pluvial e temperatura média mensal para o período de amostragem (setembro de 2000 a outubro de 2001 ), na fazenda Santa Branca, em Tibagi (PR).

estão localizadas sobre o mesmo sítio topográfico, tendo como separação apenas uma estrada interna da fazenda (carreador). Além disso, possuem o mesmo material de origem, mesma classe textural e mesma localização na vertente. Foram manejadas com práticas e rotação de culturas semelhantes.

Nestas áreas, anterior à instalação do experimento, foi feito a descrição do perfil do solo até $1,5 \mathrm{~m}$ de profundidade (SÁ, 2001). Na tabela 1, estão apresentados os resultados das principais características do horizonte diagnóstico Bw1 do Latossolo Vermelho distroférrico. Contudo, as interpretações para os resultados especialmente de estoque de $\mathrm{N}$, devem ser realizadas com cuidado pela inexistência de dados de granulometria (ex. concentração da fração argila) para as quatro profundidades amostradas nas duas áreas de estudo.

Assim, o delineamento experimental empregado foi em faixas não casualisadas com parcelas subdivididas, constando de quatro faixas (consideradas tratamentos) cada qual com cinco parcelas (pseudorepetições) (HurLberT, 1984). Cada parcela possuía $40 \mathrm{x}$ $40 \mathrm{~m}\left(1600 \mathrm{~m}^{2}\right)$ com área útil centralizada de $900 \mathrm{~m}^{2}$. Os tratamentos foram: 12 anos sob plantio direto, com as sucessões milho/trigo e soja/trigo (PD12 M/T e PD12 $\mathrm{S} / \mathrm{T}$ respectivamente) e 22 anos sob plantio direto, com as sucessões milho/trigo e soja/trigo (PD22 M/T e PD22 S / T respectivamente).

Para a caracterização físico-química, foram coletadas em cada parcela cinco pontos para formar uma amostra composta de solo para as camadas 0,000 $-0,025,0,025-0,050,0,050-0,100$ e $0,100-0,200 \mathrm{~m}$ (Tabela 2).
Tabela 1. Características do horizonte diagnóstico Bw1 em perfis de Latossolo Vermelho distoférrico nas áreas com 12 e 22 anos de SPD, em Tibagi (PR)

\begin{tabular}{lcc}
\hline Atributo do solo & PD 12 & PD 22 \\
\hline Cor (úmida) ${ }^{(1)}$ & 2,5 YR 3/6 & 2,5 YR 3/6 \\
Profundidade $(\mathrm{cm})$ & $34-80$ & $39-88$ \\
Densidade $\left(\mathrm{g} \mathrm{cm}^{-3}\right)$ & 1,46 & 1,33 \\
Estrutura & M.fina, gran. ${ }^{(5)}$ & M.fina, gran. \\
Areia $\left(\mathrm{g} \mathrm{kg}^{-1}\right)^{(2)}$ & 422 & 415 \\
Silte $\left(\mathrm{g} \mathrm{kg}^{-1}\right)^{(3)}$ & 68 & 59 \\
Argila $\left(\mathrm{g} \mathrm{kg}^{-1}\right)^{(3)}$ & 510 & 526 \\
Mineralogia & & Caolinita \\
& Gibsita & Gibsita \\
& Hematita & Hematita \\
& Goetita & Goetita \\
\hline
\end{tabular}

(1) Cor úmida (Carta de Munsell, 1954).

(2) Teores de areia determinado por peneiramento úmido (EMBRAPA, 1979).

(3) Teores de silte e argila determinados pelo método do densímetro após dispersão em hexametafosfato e digestão da matéria orgânica em $\mathrm{H}_{2} \mathrm{O}_{2}$.

$\left.{ }^{4}\right)$ Composição mineralógica da fração argila determinado por difração de raio $X$.

$\left.{ }^{5}\right)$ M.fina, gran. = estrutura muito fina e granular.

$\mathrm{O}$ pH- $\mathrm{H}_{2} \mathrm{O}$ foi determinado usando a relação solo:solução de 1:2,5. O P-disponível e os cátions trocáveis $\left(\mathrm{K}^{+}, \mathrm{Ca}^{2+}\right.$ e $\left.\mathrm{Mg}^{2+}\right)$ foram extraídos em resina trocadora de íons (RAIJ et al., 1987), sendo o P-disponível quantificado por espectrofotometria. A acidez potencial do solo foi determinada pelo método da EMBRAPA (1979). A CTC a pH 7,0 (T) e a soma bases (SB) também foram calculadas.

O plantio do milho foi realizado em setembro de 2000. A adubação de plantio foi 250 de $\mathrm{kg} \mathrm{ha}^{-1}$ 
Tabela 2. Resultados das análises de caracterização físico-química do solo nas áreas com 12 e 22 anos de SPD, em Tibagi (PR)

\begin{tabular}{|c|c|c|c|c|c|c|c|c|c|c|}
\hline Área & camada & $\mathrm{pH}$ & M.O. ${ }^{(1)}$ & P disp..$^{(2)}$ & $\mathrm{Ca}^{2+}$ & $\mathrm{Mg}^{2+}$ & $\mathrm{K}^{+}$ & $\mathrm{T}^{(3)}$ & $\mathrm{V} \%$ & $\rho^{(4)}$ \\
\hline & $(\mathrm{m})$ & & $\mathrm{g} \mathrm{kg}^{-1}$ & $\mathrm{mg} \mathrm{dm}^{-3}$ & \multicolumn{4}{|c|}{$-\mathrm{mmol}_{\mathrm{c}} \mathrm{dm}^{-3}$} & $\%$ & $\mathrm{~g} \mathrm{~cm}^{-3}$ \\
\hline \multirow[t]{4}{*}{ PD 12} & $0,000-0,025$ & 5,5 & 41 & 98 & 48 & 22 & 6,0 & 100 & 76 & 1,24 \\
\hline & $0,025-0,050$ & 5,4 & 32 & 65 & 40 & 16 & 5,3 & 83 & 74 & 1,40 \\
\hline & $0,050-0,100$ & 5,4 & 24 & 29 & 23 & 9 & 2,8 & 64 & 53 & 1,45 \\
\hline & $0,100-0,200$ & 5,3 & 33 & 18 & 17 & 11 & 2,2 & 80 & 38 & 1,44 \\
\hline \multirow[t]{4}{*}{ PD 22} & $0,000-0,025$ & 5,8 & 86 & 127 & 93 & 28 & 8,7 & 163 & 89 & 1,16 \\
\hline & $0,025-0,050$ & 5,4 & 55 & 87 & 59 & 24 & 6,6 & 128 & 70 & 1,36 \\
\hline & $0,050-0,100$ & 5,4 & 37 & 43 & 33 & 16 & 3,8 & 98 & 54 & 1,33 \\
\hline & $0,100-0,200$ & 5,4 & 21 & 17 & 15 & 7 & 1,9 & 56 & 43 & 1,32 \\
\hline
\end{tabular}

(1) M.O. = Matéria orgânica determinado pelo método de Walkley \& Black.

(2) $\mathrm{P}$ disp. = fósforo disponível determinado pelo Método da Resina.

$\left({ }^{3}\right) \mathrm{T}=$ Capacidade de troca de cátions potencial determinada a $\mathrm{pH}$ 7,0.

$\left({ }^{4}\right) \rho=$ Densidade do solo.

de 15-18-09 (NPK) com 0,75\% de sulfato de zinco. A adubação de cobertura foi realizada em outubro de 2000, com $400 \mathrm{~kg} \mathrm{ha}^{-1}$ de 20-00-10 (NPK). Em março de 2001, realizou-se a colheita obtendo-se produtividade de $8770 \mathrm{~kg} \mathrm{ha}^{-1}$. Após a colheita, a quantidade de resíduos culturais sobre o solo foi de $8200 \mathrm{~kg} \mathrm{ha}^{-1}$ (Hiraoka et al., 2002).

O plantio da soja ocorreu em outubro de 2000. A adubação de plantio foi de $200 \mathrm{~kg} \mathrm{ha}^{-1}$ de supersimples. Em janeiro de 2001, foi aplicada a adubação de cobertura com $150 \mathrm{~kg} \mathrm{ha}^{-1} \mathrm{de} \mathrm{KCl}$. A colheita foi realizada em abril de 2001, com produtividade de $3640 \mathrm{~kg} \mathrm{ha}^{-1}$. Após a colheita a quantidade de resíduos culturais sobre o solo foi de $5200 \mathrm{~kg} \mathrm{ha}^{-1}$ (HirAOKA et al., 2002).

Em maio de 2001, realizou-se a aplicação de 1,5 L ha $^{-1}$ de herbicida glifosato. Em junho de 2001, efetuouse o plantio do trigo e a adubação com $200 \mathrm{~kg}^{\mathrm{h}}{ }^{-1}$ DAP (fosfato diamônico). A adubação de cobertura foi realizada em julho de 2001, com $200 \mathrm{~kg} \mathrm{ha}^{-1}$ de 30-0020 (NPK). A colheita do trigo foi realizada em outubro de 2001, com produtividade de $3700 \mathrm{~kg} \mathrm{ha}^{-1}$. Após a colheita, a quantidade de resíduos culturais sobre o solo foi de $11600 \mathrm{~kg} \mathrm{ha}^{-1}$ na sucessão milho/trigo, e de 9400 $\mathrm{kg} \mathrm{ha}^{-1}$ na sucessão soja/trigo (HIRAOKA et al., 2002).

As principais práticas agrícolas e o tempo decorrido antes de cada amostragem realizadas nas áreas de estudos estão apresentados na tabela 3.

Os teores de N-total foram determinados após a colheita do milho e da soja (maio de 2001), e após a colheita do trigo (outubro de 2001). As amostras foram secas ao ar, homogeneizadas, moídas, passadas em peneiras a 100 mesh e analisadas por combustão a seco pelo equipamento LECO CN-2000. A densidade do solo $(\rho)$ foi determinada em amostras indeformadas coletadas sem anéis de aço inox com diâmetro de $5 \mathrm{~cm}$ e alturas de 0,025 m para as camadas de 0,000-0,025 e $0,025-0,050 \mathrm{~m}$, e altura de $0,050 \mathrm{~m}$ para as camadas 0,050 -
0,100; 0,100-0,200 m. No laboratório, foi determinada a massa total das amostras e uma subamostra de $5 \mathrm{~g}$ foi seca até massa constante a $105^{\circ} \mathrm{C}$ para determinação da umidade gravimétrica. Calculou-se a densidade do solo com a massa do solo e o volume do cilindro utilizado na amostragem (BLAKE e HARTGE, 1986).

Os estoques de $\mathrm{N}$ foram calculados a partir dos teores de $\mathrm{N}$, os valores da densidade do solo e das camadas de solos (Equação 1) (BERNoux et al., 1998).

$\mathrm{E}=\rho \cdot \mathrm{h} . \mathrm{N}$

Equação (1)

em que $\mathrm{E}$ é o estoque de $\mathrm{N}$ do solo $\left(\mathrm{Mg} \mathrm{ha}^{-1}\right) ; \rho$ é a densidade do solo; h é a espessura da camada amostrada e; $\mathrm{N}$ é o teor de carbono do solo.

Contudo, como neste estudo o objetivo foi comparar tratamentos com diferentes tempos de implantação do SPD e, uma vez que nas áreas amostradas haviam valores diferentes na densidade do solo, foi realizada a correção do estoque de $\mathrm{N}$ do solo pela massa amostrada na área com menor densidade do solo (Equação 2) (SIsTI et al., 2004).

$\mathrm{EN}=\sum^{\mathrm{n}-\mathrm{i}} \mathrm{E}+\left\{\left[\mathrm{Mai}-\left(\sum^{\mathrm{n}} \mathrm{Ma}-\sum^{\mathrm{n}} \mathrm{Mr}\right)\right] . \mathrm{Ni}\right\} \quad$ Equação (2)

em que: EN é o estoque corrigido de $\mathrm{N}$ pela massa de solo $\left(\mathrm{Mg} \mathrm{ha}{ }^{-1}\right) ; \sum^{\mathrm{n}-\mathrm{E}} \mathrm{E}$ é o somatório dos estoques das camadas, sem a última camada amostrada; Mai é a massa de solo da última camada de solo amostrado; $\sum^{\mathrm{n}} \mathrm{Ma}$ é o somatório da massa total de solo amostrada; $\sum^{\mathrm{n}} \mathrm{Mr}$ é o somatório da massa de solo referência e; $\mathrm{Ni}$ é teor de $\mathrm{N}$ na última camada amostrada.

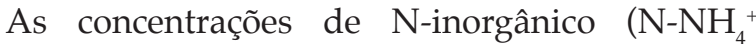
e $\mathrm{N}^{-\mathrm{NO}_{3}^{-}}$) foram determinadas em solução de $\mathrm{KCl}$ (2 mol L-1) usando a relação solo:solução de 1:5 que 
Tabela 3. Época das amostragens de solo para determinação de N-total, N-inorgânico e óxido nitroso nas diferentes condições de cobertura do solo, principais tratos culturais durante experimento em campo com 12 e 22 anos de implantação do SPD nas sucessões milho/trigo e soja/trigo realizada na Fazenda Santa Branca, em Tibagi (PR)

\begin{tabular}{|c|c|c|c|c|c|c|c|}
\hline \multirow[t]{2}{*}{ Época } & \multirow[t]{2}{*}{ Determinações } & \multirow{2}{*}{$\begin{array}{l}\text { Resíduos culturais / } \\
\text { Cultura }\end{array}$} & \multirow[t]{2}{*}{ Tratos culturais ${ }^{(1)}$} & \multirow[t]{2}{*}{ Data $^{(2)}$} & \multicolumn{2}{|c|}{ Tempo até a amostragem ${ }^{(3)}$} & \multirow{2}{*}{$\begin{array}{l}\text { Condições } \\
\text { climáticas }\end{array}$} \\
\hline & & & & & Milho/Trigo & Soja/Trigo & \\
\hline \multirow[t]{2}{*}{ Set/00 } & \multirow[t]{2}{*}{$\begin{array}{l}\text { Caracterização } \\
\text { e N-inorgânico }\end{array}$} & \multirow[t]{2}{*}{$\begin{array}{l}\text { Resíduos de aveia } \\
\text { preta / sem cultura. }\end{array}$} & $\begin{array}{l}\text { Aplicação de herbicida + } \\
\text { inseticida }\end{array}$ & & \multirow[t]{2}{*}{ Anterior $^{(4)}$} & \multirow[t]{2}{*}{ Anterior } & \multirow[t]{2}{*}{$\begin{array}{l}\text { Ensolarado } \\
\text { com ventos }\end{array}$} \\
\hline & & & $\begin{array}{l}\text { Plantio do milho e adubação } \\
\text { NPK }\end{array}$ & $27 / 09 / 00$ & & & \\
\hline \multirow[t]{3}{*}{ Out/00 } & \multirow[t]{3}{*}{ N-inorgânico } & \multirow{3}{*}{$\begin{array}{l}\text { Resíduos de aveia } \\
\text { preta / milho em fase } \\
\text { vegetativa. }\end{array}$} & Adubação cobertura no milho & $15 / 10 / 00$ & \multirow{3}{*}{$\begin{array}{l}15 \text { dias após } \\
\text { plantio }\end{array}$} & \multirow[t]{3}{*}{ n.d. } & \multirow{3}{*}{$\begin{array}{l}\text { Nublado/ } \\
\text { chuvoso }\end{array}$} \\
\hline & & & $\begin{array}{l}\text { Aplicação de herbicida }+ \\
\text { inseticida }\end{array}$ & $24 / 10 / 00$ & & & \\
\hline & & & Plantio da soja e adubação PK & $25 / 10 / 00$ & & & \\
\hline Nov/00 & N-inorgânico & $\begin{array}{l}\text { Resíduos de aveia } \\
\text { preta / milho e soja em } \\
\text { fase vegetativa. }\end{array}$ & --- & $\ldots$ & $\begin{array}{l}30 \text { dias após } \\
\text { adubação }\end{array}$ & $\begin{array}{l}20 \text { dias após } \\
\text { plantio }\end{array}$ & Chuvoso \\
\hline Dez/00 & $\begin{array}{l}\text { N-inorgânico, } \\
\mathrm{N}-\mathrm{N}_{2} \mathrm{O}\end{array}$ & $\begin{array}{l}\text { Resíduos de aveia } \\
\text { preta / milho e soja em } \\
\text { fase reprodutiva. }\end{array}$ & --- & $\cdots$ & $\begin{array}{l}63 \text { dias após } \\
\text { adubação }\end{array}$ & $\begin{array}{l}50 \text { dias após } \\
\text { plantio }\end{array}$ & Chuvoso \\
\hline \multirow[t]{2}{*}{$\mathrm{Fev} / 01$} & \multirow[t]{2}{*}{$\mathrm{N}$-inorgânico } & \multirow{2}{*}{$\begin{array}{l}\text { Resíduos de aveia } \\
\text { preta / milho e soja em } \\
\text { fase de maturação. }\end{array}$} & Colheita do milho & $10 / 03 / 01$ & \multirow[t]{2}{*}{ Anterior } & \multirow[t]{2}{*}{ Anterior } & \multirow{2}{*}{$\begin{array}{l}\text { Nublado/ } \\
\text { chuvoso }\end{array}$} \\
\hline & & & Colheita da soja & $11 / 04 / 01$ & & & \\
\hline Mai/01 & $\begin{array}{l}\mathrm{N} \text {-inorgânico, } \\
\mathrm{N} \text {-total e } \\
\mathrm{N}-\mathrm{N}_{2} \mathrm{O}\end{array}$ & $\begin{array}{l}\text { Resíduos de milho e } \\
\text { soja. }\end{array}$ & $\begin{array}{l}\text { Aplicação de herbicida + } \\
\text { inseticida }\end{array}$ & . & Anterior & Anterior & Ensolarado \\
\hline \multirow[t]{2}{*}{ Jun/01 } & \multirow[t]{2}{*}{$\begin{array}{l}\text { N-inorgânico e } \\
\mathrm{N}-\mathrm{N}_{2} \mathrm{O}\end{array}$} & \multirow{2}{*}{$\begin{array}{l}\text { Resíduos de milho e } \\
\text { soja / trigo em fase } \\
\text { vegetativa. }\end{array}$} & $\begin{array}{l}\text { Plantio do trigo e adubação } \\
\text { NPK }\end{array}$ & $04 / 06 / 00$ & \multirow[t]{2}{*}{$\begin{array}{l}20 \text { dias após } \\
\text { plantio }\end{array}$} & \multirow[t]{2}{*}{$\begin{array}{l}20 \text { dias após } \\
\text { plantio }\end{array}$} & \multirow[t]{2}{*}{$\begin{array}{l}\text { Nublado/ } \\
\text { chuvoso }\end{array}$} \\
\hline & & & Adubação de cobertura NPK & $07 / 07 / 00$ & & & \\
\hline Ago/01 & $\begin{array}{l}\mathrm{N} \text {-inorgânico e } \\
\mathrm{N}-\mathrm{N}_{2} \mathrm{O}\end{array}$ & $\begin{array}{l}\text { Resíduos de milho e } \\
\text { soja / trigo em fase } \\
\text { vegetativa. }\end{array}$ & $\begin{array}{l}\text { Aplicação de herbicida }+ \\
\text { inseticida }\end{array}$ & .. & $\begin{array}{l}50 \text { dias após } \\
\text { adubação }\end{array}$ & $\begin{array}{l}50 \text { dias após } \\
\text { adubação }\end{array}$ & Nublado \\
\hline Out/01 & $\begin{array}{l}\text { N-inorgânico, } \\
\text { N-total e } \\
\mathrm{N}-\mathrm{N}_{2} \mathrm{O}\end{array}$ & Resíduos de trigo. & Colheita do trigo & $23 / 10 / 01$ & $\begin{array}{l}1 \text { dia após } \\
\text { colheita }\end{array}$ & $\begin{array}{l}1 \text { dia após } \\
\text { colheita }\end{array}$ & Ensolarado \\
\hline
\end{tabular}

$\left({ }^{1}\right)=---=$ sem ocorrências. $\left({ }^{2}\right) \ldots=$ data desconhecida. $\left({ }^{3}\right)$ n.d. = não determinado. $\left({ }^{4}\right)$ Anterior = ocorrência do evento anterior à amostragem de solo ou gases.

foi agitada por 5 minutos e filtrada após 24 horas. As concentrações de N-amônio e N-nitrato nos extratos foram determinadas usando um sistema automático de injeção em fluxo (FIA) (RuzickA e HANSEN, 1981). $\mathrm{O} \mathrm{N}_{-} \mathrm{NH}_{4}^{+}$foi medido por condutivimetria pelo método de Solorzano (1969) e o $\mathrm{N}^{-\mathrm{NO}_{3}}$ - determinado colorimetricamente na forma de $\mathrm{N}-\mathrm{NO}_{2}^{-}$, após a redução com o catalisador cádmio.

Para determinar as taxas líquidas de mineralização e nitrificação, as amostras de solo permaneceram incubadas no laboratório a $25^{\circ} \mathrm{C}$ por um período de sete dias. Passado o período de incubação repetiram-se as determinações das concentrações do N-inorgânico.

A taxa líquida de mineralização do $\mathrm{N}$ foi calculada pela alteração na concentração do N-inorgânico do solo durante o período de incubação das amostras de solo. A taxa líquida de nitrificação corresponde à variação na concentração do N-nitrato, durante o período de incubação das amostras de solo (PicCOLO et al., 1994).
As amostras de gases para determinar as emissões de $\mathrm{N}-\mathrm{N}_{2} \mathrm{O}$ provenientes do solo foram realizadas em cinco épocas (dezembro de 2000, maio, junho, agosto e outubro de 2001).

As amostragens do fluxo de $\mathrm{N}_{2} \mathrm{O}$ foram feitas em três câmaras segundo a concepção de BowDEn et al., 1990. $\mathrm{O}$ espaçamento entre as bases foi de aproximadamente 5 metros conservando-se a cobertura do solo (resíduos culturais). Colocando-se as tampas sobre as bases de maneira a isolar o ambiente interno do externo no momento da amostragem. As amostras de gases provenientes do solo foram coletadas em seringas de nylon de $20 \mathrm{~mL}$ em intervalos de tempo pré-estabelecidos $(0,5,10$ e 20 minutos), com as medidas feitas duas vezes ao dia. A determinação do $\mathrm{N}-\mathrm{N}_{2} \mathrm{O}$ foi realizada por cromatografia gasosa em coluna empacotada operando a $65^{\circ} \mathrm{C}$ com uma fonte de ${ }^{63} \mathrm{Ni}$ para a ionização do gás e medido por um detector de captura de elétrons (ECD), operando a $280^{\circ} \mathrm{C}$ no equipamento Shimadzu ${ }^{\circledR}$ GC-14A. 
A calibração do equipamento foi realizada com dois padrões certificados White-Martins com concentrações mínimas e máximas, respectivamente, de 292 e 1115 ppbv. Os fluxos foram calculados pela alteração linear da concentração do gás com o tempo de incubação (Equação 3).

Fluxo $=(\delta[g a ́ s] / \delta t) .\left(V_{h} / A\right) \cdot\left((1-e / P) / V_{M}\right) \quad$ Equação (3)

em que ( $\delta$ [gás]/ $\delta t)$ é a alteração da concentração do gás em função do tempo (mol gás $\left.\mathrm{mol}^{-1} \mathrm{~s}^{-1}\right) ; \mathrm{V}_{\mathrm{h}}$ é $\mathrm{o}$ volume da câmara utilizada na amostragem $\left(\mathrm{m}^{3}\right)$; A é a área da câmara $\left(\mathrm{m}^{2}\right)$; e/ $\mathrm{P}$ é a pressão de água/pressão atmosférica na câmara $\left(\mathrm{kPa} \mathrm{kPa}^{-1}\right) ; \mathrm{V}_{\mathrm{M}}$ é o Volume molar da câmara $\left(\mathrm{m}^{3} \mathrm{~mol}^{-1}\right)$.

Os resultados foram submetidos à análise de variância pelo procedimento GLM (General Linear Model Procedure) e as médias comparadas pelo teste de Tukey $(\mathrm{p}<0,05)$.

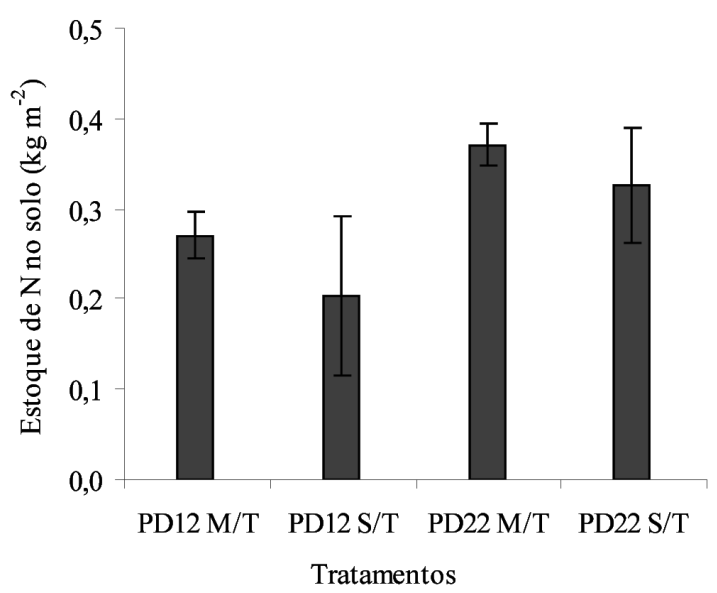

Figura 2. Estoque de $\mathrm{N}$ no solo $\left(\mathrm{kg} \mathrm{m}^{-2}\right)$ sob 12 e 22 anos com SPD nas sucessões milho/trigo $(\mathrm{M} / \mathrm{T})$ e soja/trigo $(\mathrm{S} / \mathrm{T})$, para camada $0,000-0,200 \mathrm{~m}$. Os resultados representam a média $(n=20) \pm$ desvio-padrão.

\section{RESULTADOS E DISCUSSÕES}

\section{N-total do solo}

Os teores de $\mathrm{N}$-total nos solos foram maiores na camada superficial e decresceram com a profundidade em todos os tratamentos $(\mathrm{p}<0,05)$ (Tabela 4).

Nos tratamentos com 22 anos de SPD contataramsemaiores teores de $\mathrm{N}$-total em todas as camadas amostradas $(p<0,05)$. Contudo, na sucessão milho/ trigo foram observados os teores mais elevados de $\mathrm{N}$ principalmente nas camadas 0,000 - 0,025 e 0,025 - 0,050 $\mathrm{m}$. Esse fato pode ter ocorrido devido à maior presença de resíduos culturais de milho particulado, que passam a fazer parte do solo, sem o processo de decomposição e humificação; contudo, quando analisados por combustão podem aumentar os teores de C e N.

Além disso, a aplicação de $\mathrm{N}$-fertilizante no milho pode favorecer a estabilização da MOS com o acúmulo tanto de C como de N no solo (Lovato et al., 2004, DieKOW et al., 2005) em decorrência da presença de um material com elevada relação C:N (MARQuEZ et al., 2000).

A permanência dos resíduos culturais em superfície, a rotação de culturas e o não-revolvimento do solo favorecem a proteção física da MOS com a formação de agregados que ocasionam o aumento dos estoques de C e N no solo (SÁ et al., 2001). Diversos estudos (BAYER et al., 2000; LovATO et al., 2004; Sisti et al., 2004; DiEKOW et al., 2005) mostraram aumentos nas quantidades de C e $\mathrm{N}$ significativos nas camadas superficiais do solo nos anos iniciais do SPD, mas com o tempo de manejo os estoques aumentaram nas camadas mais profundas.

O comportamento distinto entre as sucessões milho/trigo e soja / trigo nos teores de N-total refletiram no estoque do N no solo (Figura 2).

\section{N-inorgânico no solo}

As quantidades de $\mathrm{N}$-nitrato, de modo geral, representaram em média $60 \%$ do $\mathrm{N}$-inorgânico no solo em todos os tratamentos, principalmente na sucessão

Tabela 4. Teores de N-total no solo $\left(\mathrm{g} \mathrm{kg}^{-1}\right)$ com 12 e 22 anos de SPD nas sucessões milho/trigo (M/T) e soja/trigo (S/T) para as diferentes camadas de solo amostradas, em Tibagi (PR)

\begin{tabular}{|c|c|c|c|c|}
\hline \multirow[t]{2}{*}{ Camada } & \multicolumn{2}{|c|}{ PD 12} & \multicolumn{2}{|c|}{ PD 22} \\
\hline & $\mathrm{M} / \mathrm{T}$ & $\mathrm{S} / \mathrm{T}$ & $\mathrm{M} / \mathrm{T}$ & $\mathrm{S} / \mathrm{T}$ \\
\hline $\mathrm{m}$ & & 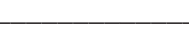 & 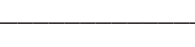 & $x_{1}$ \\
\hline $0,000-0,025$ & $1,63 \pm 0,09 b$ & $1,65 \pm 0,21 b$ & $2,68 \pm 0,04 \mathrm{a}$ & $2,27 \pm 0,05 \mathrm{a}$ \\
\hline $0,025-0,050$ & $1,41 \pm 0,13 b$ & $1,07 \pm 0,14 \mathrm{c}$ & $2,32 \pm 0,10 a$ & $1,52 \pm 0,11 b$ \\
\hline $0,050-0,100$ & $0,79 \pm 0,02 \mathrm{c}$ & $0,64 \pm 0,16 \mathrm{c}$ & $1,34 \pm 0,01 \mathrm{a}$ & $1,20 \pm 0,03 \mathrm{~b}$ \\
\hline $0,100-0,200$ & $0,78 \pm 0,06 \mathrm{~b}$ & $0,48 \pm 0,08 \mathrm{~b}$ & $0,97 \pm 0,03 \mathrm{a}$ & $1,00 \pm 0,05 \mathrm{a}$ \\
\hline
\end{tabular}

Os resultados representam a média $(n=5) \pm$ erro-padrão. Médias seguidas de mesma letra na linha não diferem significativamente no teste de Tukey $(\mathrm{p}<0,05)$. 
Tabela 5. Teores médios de $\mathrm{N}$-amônio, $\mathrm{N}$-nitrato, $\mathrm{N}$-inorgânico $\left(\mathrm{mg} \mathrm{kg}^{-1}\right)$, taxas líquidas de mineralização e nitrificação do $\mathrm{N}$ no solo $\left(\mathrm{mg} \mathrm{kg}^{-1} \mathrm{~d}^{-1}\right)$ com 12 e 22 anos de SPD nas sucessões milho/trigo (M/T) e soja/trigo (S/T), em Tibagi (PR)

\begin{tabular}{|c|c|c|c|c|}
\hline \multirow[t]{2}{*}{ Camada } & \multicolumn{2}{|c|}{ PD 12} & \multicolumn{2}{|c|}{ PD 22} \\
\hline & $\mathrm{M} / \mathrm{T}$ & $\mathrm{S} / \mathrm{T}$ & $\mathrm{M} / \mathrm{T}$ & $\mathrm{S} / \mathrm{T}$ \\
\hline $\mathrm{m}$ & \multicolumn{4}{|c|}{ N-amônio no solo $\left(\mathrm{mg} \mathrm{kg}^{-1}\right)$} \\
\hline $0,000-0,025$ & $6,07 \pm 1,71 \mathrm{ab}$ & $4,70 \pm 0,83 b$ & $10,56 \pm 2,29 a$ & $7,89 \pm 1,41 \mathrm{ab}$ \\
\hline $0,025-0,050$ & $3,71 \pm 0,88 \mathrm{~b}$ & $3,25 \pm 0,86 b$ & $6,15 \pm 1,53 \mathrm{a}$ & $4,45 \pm 0,83 \mathrm{ab}$ \\
\hline $0,050-0,100$ & $5,59 \pm 2,70 a$ & $3,39 \pm 1,30 \mathrm{~b}$ & $4,50 \pm 1,09 \mathrm{a}$ & $2,77 \pm 0,66 \mathrm{~b}$ \\
\hline \multirow[t]{2}{*}{$0,100-0,200$} & $4,64 \pm 2,72 \mathrm{a}$ & $1,85 \pm 0,49 b$ & $3,32 \pm 0,78 a b$ & $2,21 \pm 0,47 \mathrm{~b}$ \\
\hline & \multicolumn{4}{|c|}{ _ N-nitrato no solo $\left(\mathrm{mg} \mathrm{kg}^{-1}\right)$} \\
\hline $0,000-0,025$ & $7,58 \pm 0,83 b$ & $7,03 \pm 1,29 b$ & $11,84 \pm 1,80 \mathrm{a}$ & $8,94 \pm 1,69 a b$ \\
\hline $0,025-0,050$ & $5,37 \pm 0,69 \mathrm{~b}$ & $4,90 \pm 0,90 \mathrm{~b}$ & $8,59 \pm 1,22 \mathrm{a}$ & $7,42 \pm 1,56 \mathrm{a}$ \\
\hline $0,050-0,100$ & $3,93 \pm 0,79 b$ & $4,05 \pm 1,10 b$ & $5,46 \pm 1,02 \mathrm{a}$ & $5,24 \pm 1,34 \mathrm{a}$ \\
\hline \multirow[t]{2}{*}{$0,100-0,200$} & $3,88 \pm 1,04 b$ & $4,04 \pm 1,21 b$ & $6,35 \pm 2,12 \mathrm{a}$ & $5,66 \pm 1,64 \mathrm{a}$ \\
\hline & \multicolumn{4}{|c|}{ - N-inorgânico no solo $\left(\mathrm{mg} \mathrm{kg}^{-1}\right)$} \\
\hline $0,000-0,025$ & $13,64 \pm 1,96 \mathrm{bc}$ & $11,73 \pm 1,68 \mathrm{c}$ & $22,40 \pm 3,32 \mathrm{a}$ & $16,83 \pm 2,68 b$ \\
\hline $0,025-0,050$ & $9,08 \pm 1,04 \mathrm{bc}$ & $8,15 \pm 1,40 \mathrm{c}$ & $14,74 \pm 2,14 \mathrm{a}$ & $11,87 \pm 2,13 \mathrm{ab}$ \\
\hline $0,050-0,100$ & $9,53 \pm 2,78 \mathrm{a}$ & $7,44 \pm 1,99 b$ & $9,95 \pm 1,41 \mathrm{a}$ & $8,01 \pm 1,80 \mathrm{~b}$ \\
\hline $0,100-0,200$ & $8,53 \pm 2,83 \mathrm{a}$ & $5,89 \pm 1,37 b$ & $9,67 \pm 1,98 \mathrm{a}$ & $7,87 \pm 1,91 \mathrm{ab}$ \\
\hline $0,000-0,025$ & $2,09 \pm 0,19 a$ & $1,75 \pm 0,35 a$ & $2.87 \pm 0.55 a$ & $249+067 a$ \\
\hline $0,025-0,050$ & $1,32 \pm 0,13 \mathrm{ab}$ & $0,99 \pm 0,20 \mathrm{~b}$ & $1,71 \pm 0,24 \mathrm{a}$ & $1,47 \pm 0,36 \mathrm{a}$ \\
\hline $0,050-0,100$ & $0,59 \pm 0,12 \mathrm{a}$ & $0,74 \pm 0,27 \mathrm{a}$ & $0,74 \pm 0,23 \mathrm{a}$ & $0,83 \pm 0,22 \mathrm{a}$ \\
\hline \multirow[t]{2}{*}{$0,100-0,200$} & $0,25 \pm 0,12 b$ & $0,31 \pm 0,15 \mathrm{a}$ & $0,29 \pm 0,31 \mathrm{a}$ & $0,42 \pm 0,23 \mathrm{a}$ \\
\hline & & a líquida de nit & no solo $\left(\mathrm{mg} \mathrm{kg}^{-1}\right.$ & \\
\hline $0,000-0,025$ & $1,82 \pm 0,24 \mathrm{c}$ & $1,61 \pm 0,32 \mathrm{c}$ & $3,14 \pm 0,48 a$ & $2,37 \pm 0,55 \mathrm{~b}$ \\
\hline $0,025-0,050$ & $0,97 \pm 0,12 b$ & $0,99 \pm 0,19 b$ & $1,79 \pm 0,17 \mathrm{a}$ & $1,49 \pm 0,30 \mathrm{a}$ \\
\hline $0,050-0,100$ & $0,59 \pm 0,10 b$ & $0,57 \pm 0,13 b$ & $1,11 \pm 0,24 \mathrm{a}$ & $0,81 \pm 0,18 \mathrm{ab}$ \\
\hline $0,100-0,200$ & $0,29 \pm 0,07 b$ & $0,27 \pm 0,11 b$ & $0,61 \pm 0,30 \mathrm{a}$ & $0,47 \pm 0,13 \mathrm{a}$ \\
\hline
\end{tabular}

Os valores representam à média $(\mathrm{n}=45) \pm$ erro-padrão. Médias seguidas de mesma letra na linha não diferem significativamente no teste de Tukey $(\mathrm{p}<0,05)$.

soja/trigo independentemente do tempo de implantação do SPD (Tabela 5). REMBON e MACKENZIE (1997) também constataram que os resíduos de soja aumentaram as quantidades de N-nitrato no solo sob SPD. KRIFT e BERENDSE (2001) verificaram maior mineralização de $\mathrm{N}$ em espécies com maior quantidade de $\mathrm{N}$ na composição dos resíduos culturais. Além disso, houve nitrificação maior e mais rápida com disponibilização de $\mathrm{N}$-nitrato, ao passo que resíduos com menor quantidade de $\mathrm{N}$ em sua composição foram mais lento na ciclagem do $\mathrm{N}$ no solo.

As maiores quantidades médias de $\mathrm{N}$-inorgânico no solo, de maneira geral, foram observadas nos tratamentos com maior tempo sob SPD, revelando diferenças estatisticamente significativas $(p<0,05)$ principalmente na sucessão milho / trigo. A concentração de N-inorgânico no solo e o tempo de implantação deste sistema de cultivo mostraram uma ligação com o maior teor de MOS acumulado.

Em relação às médias para as diferentes profundidades estudadas, as quantidades de $\mathrm{N}$-amônio foram mais elevadas na camada de 0,000 -
0,025 m com seus valores decrescendo no perfil do solo (Tabela 5). Este comportamento foi possível devido à deposição dos resíduos culturais na superfície do solo, promovendo maior ciclagem do nutriente nesta camada, além desta forma do elemento apresentar cargas positivas e poder integrar os complexos de cargas do solo (CTC), normalmente mais elevado devido à presença da MOS. O mesmo comportamento foi verificado para o N-nitrato, porém com menor estratificação nas camadas mais profundas do solo (Tabela 5).

A quantidade de N-inorgânico constatada no solo representou em média $0,82 \pm 0,13 \%$ do estoque de $\mathrm{N}$ no solo. Contudo, não foram verificadas alterações significativas nesta fração de $\mathrm{N}$-inorgânico em relação ao N-total devido à sucessão de culturas ou o tempo de implantação do SPD.

Em outubro de 2000, foram observadas as maiores quantidades de $\mathrm{N}$-inorgânico $(0,000-0,200 \mathrm{~m})$ no SPD com 22 anos na sucessão milho/trigo $\left(6,7 \mathrm{~g} \mathrm{~m}^{-2}\right.$ de $\left.\mathrm{N}\right)$, principalmente na forma de $\mathrm{N}$-amônio, provavelmente 

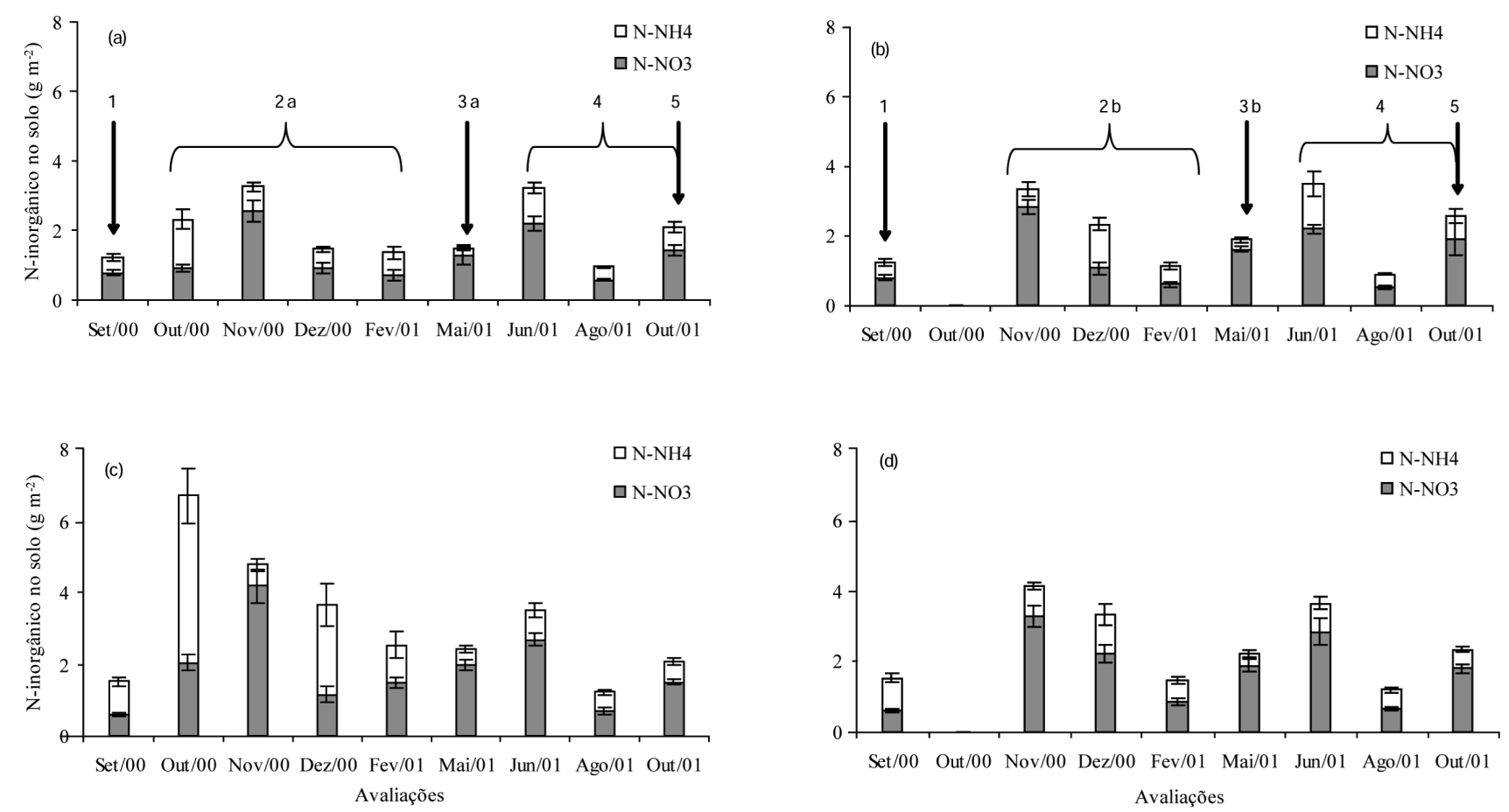

Figura 3. N-inorgânico (N-amônio e N-nitrato) no solo $\left(\mathrm{g} \mathrm{m}^{-2}\right)$ sob 12 anos com SPD nas sucessões: A) milho/trigo (PD12 M/T); B) soja/trigo (PD12 S/T) e sob 22 anos de SPD nas sucessões: C) milho/trigo (PD22 M/T) e, D) soja/trigo (PD22 S/T), para a camada 0,000-0,200 m no município de Tibagi (PR). Os resultados representam a média $(\mathrm{n}=20) \pm$ desvio-padrão. Nota - Os números correspondem à cultura ou resíduo cultural que recobria o solo no período da amostragem: (1) Resíduo de aveia preta; (2) Culturas de Verão em (a) milho e, em (b) soja; (3) Resíduos culturais das culturas de Verão em (a) milho e, em (b) soja; (4) Cultura de Inverno: trigo para todos os tratamentos; (5) Resíduos culturais do trigo, colhido no dia anterior a amostragem das áreas.

devido à adubação realizada no plantio e na cobertura do milho com sulfato de amônio. Contudo, não foi observado o mesmo aumento para o SPD com 12 anos, o menor valor anotado pode ser devido à imobilização do $\mathrm{N}$-fertilizante, posteriormente confirmado com os valores médios de $\mathrm{N}$-inorgânico no solo observado em novembro de 2000 (Figura 3a,c).

Ao mesmo tempo, não se pode descartar que o solo com 22 anos sob SPD tenha maior quantidade de $\mathrm{N}$ e, provavelmente, maior ciclagem deste nutriente, fazendo com que as concentrações de $\mathrm{N}$-inorgânico no solo possam tender a ser maior que no solo com menor teor de MOS, na maior parte do período amostrado.

Com o desenvolvimento do milho foram observadas reduções nas quantidades de $\mathrm{N}$-inorgânico no solo que deve ter acontecido em decorrência da absorção de nutrientes pelas plantas. Este decréscimo ocorreu até fevereiro de 2001 quando a cultura estava na fase de grãos maduros e já apresentava sinais de senescência. Ros et al. (2003) também verificaram redução na disponibilidade de N-inorgânico no solo com o desenvolvimento do milho, mesmo quando o N-fertilizante foi aplicado em diferentes doses e épocas.
Após a colheita do milho (maio de 2001), as áreas permaneceram cobertas com os resíduos culturais. Neste período, o N-inorgânico no solo não sofreu alteração em relação a fevereiro de 2001, constatando-se uma quantidade remanescente de 1,4 e $2,5 \mathrm{~g} \mathrm{~m}^{-2}$ de $\mathrm{N}$ no solo nos tratamentos com 12 e 22 anos respectivamente.

Em junho de 2001, foi realizado o plantio do trigo, e a adubação foi realizada com sulfato de amônio, porém, no período da amostragem do solo, o $\mathrm{N}$-inorgânico já estava em grande parte na forma de $\mathrm{N}$-nitrato, provavelmente, pela ocorrência do processo de nitrificação do $\mathrm{N}$-amônio do fertilizante (Figura 3a,c). O mesmo foi observado por MARQuEZ et al. (2000), estudando a imobilização e liberação do $\mathrm{N}$-fertilizante em solos sob diferentes manejos, com e sem resíduos culturais.

O N-inorgânico do solo nos tratamentos com milho/trigo decresceu em agosto de 2001, provavelmente,devido à absorção de $\mathrm{N}$ pelo trigo, contudo em outubro de 2001, com o fim do ciclo e a colheita da cultura ocorreram aumentos significativos no $\mathrm{N}$-inorgânico principalmente na forma de $\mathrm{N}$-nitrato (Figura 3a,c). O remanescente de $\mathrm{N}$-inorgânico, após a 
colheita do trigo foi aproximadamente de $2,1 \mathrm{~g} \mathrm{~m}^{-2}$ de $\mathrm{N}$ para os dois tempos de implantação do SPD.

Para a sucessão soja/trigo, em novembro de 2000, foram observadas as maiores quantidades de $\mathrm{N}$-inorgânico no solo sendo 3,3 e 4,1 $\mathrm{g} \mathrm{m}^{-2}$ de $\mathrm{N}$ para os tratamentos com 12 e 22 anos respectivamente. A forma de $\mathrm{N}$-inorgânico mais abundante foi o $\mathrm{N}$-nitrato, que correspondeu entre 60\% e 80\% (Figura 3b,d).

Com o desenvolvimento da soja, a quantidade de $\mathrm{N}$-inorgânico no solo foi diminuindo gradativamente no solo até fevereiro de 2001, quando a cultura estava em fase de enchimento dos grãos e necessidade de grande demanda de nutrientes.

Em maio de 2001, após a colheita e o recobrimento do solo com os resíduos culturais da soja, ocorreu a elevação no $\mathrm{N}$-inorgânico, permanecendo no solo 1,8 e $2,2 \mathrm{~g} \mathrm{~m}^{-2}$ de $\mathrm{N}$ nos tratamentos com 12 e 22 anos, respectivamente. $\mathrm{O} \mathrm{N}$-nitrato neste período representou aproximadamente $85 \%$ do $\mathrm{N}$-inorgânico contido no solo. Este aumento do N-inorgânico em relação a fevereiro de 2001 pode ser explicado pelo maior grau de decomponibilidade dos resíduos culturais da soja com menor relação C:N $(\approx 28)$, consequentemente mineralização do $\mathrm{N}$ contido nestes resíduos (GLASENER et al., 2002).

MARQueZ et al. (2000) constataram maiores quantidades de $\mathrm{N}$-nitrato em relação ao $\mathrm{N}$-amônio em solos incubados com resíduos de lablabe (Dolichos lablab L.), enquanto em solos com resíduos de milho houve maiores teores de $\mathrm{N}$-amônio no período inicial da incubação (25 dias) com aumento do N-nitrato após este período. Em estudos de Dou et al. (1995) e REMBON e MACKenZIE (1997) constatou-se que os resíduos de culturas leguminosas aumentaram os teores de $\mathrm{N}$-nitrato no solo e, houve redução de 40 a $60 \%$ na quantidade de $\mathrm{N}$ aplicado na cultura do milho em sucessão.

Em junho de 2001, foi realizado o plantio de trigo, e a adubação com sulfato de amônio, porém no período da amostragem, o N-inorgânico no solo, assim como na sucessão milho/trigo, já estava predominantemente na forma de $\mathrm{N}_{-} \mathrm{NO}_{3}$. Em agosto de 2001 ocorreu decréscimo no N-inorgânico no solo, provavelmente devido à extração pela cultura do trigo.

As quantidades de N-inorgânico aumentaram principalmente na forma de $\mathrm{N}$-nitrato e, após a colheita do trigo (outubro de 2001), o N-inorgânico proporcionou uma quantidade remanescente no solo de 2,6 e 2,3 $\mathrm{g} \mathrm{m}^{-2}$ de $\mathrm{N}$, respectivamente para os tratamentos com 12 e 22 anos. KRISTENSEN et al. (2003) estudando o efeito do manejo na mineralização de $\mathrm{N}$, verificaram $4,3 \mathrm{~g} \mathrm{~m}^{-2}$ de $\mathrm{N}$ remanescente no solo depois de 10 dias da colheita da aveia cultivada em SPD.

\section{Taxas líquidas de mineralização e nitrificação do $\mathrm{N}$ no solo}

As maiores taxas líquidas de mineralização e nitrificação do $\mathrm{N}$ no solo foram observadas na camada de 0,000-0,025 m e decresceram com o aumento da profundidade (Tabela 5). Essa taxa pode estar associada à maior atividade microbiana nesta camada, devido a estar mais sujeita à contribuição dos resíduos culturais, maiores teores de MOS, melhor aeração e a aplicação de calcário e demais nutrientes em superfície neste sistema de cultivo.

As taxas médias de mineralização e nitrificação do $\mathrm{N}$ no solo não tiveram diferenças estatisticamente significativas $(p<0,05)$ para as sucessões estudadas. As médias avaliadas no período estudado para a mineralização e a nitrificação foram de 0,22 e 0,24 $\mathrm{g} \mathrm{m}^{-2}$ $\mathrm{dia}^{-1}$, respectivamente.

No tempo de duração do SPD houve diferenças estatisticamente significativas $(p<0,05)$ para as taxa médias de mineralização e nitrificação. As médias para a mineralização foram de 0,19 e 0,26 $\mathrm{g} \mathrm{m}^{-2} \mathrm{dia}^{-1}$ para o SPD com 12 e 22 anos respectivamente. Para a nitrificação as médias foram de 0,18 e $0,29 \mathrm{~g} \mathrm{~m}^{-2} \mathrm{dia}^{-1}$ para 12 e 22 anos respectivamente, em decorrência, provavelmente dos maiores teores de MOS nas áreas com maior tempo de implantação do SPD (SÁ et al., 2001) e quantidades mais elevadas de N-total no solo (AMADO et al., 2001).

KRISTENSEN et al. (2003) verificaram taxa de mineralização de $0,12 \mathrm{~g} \mathrm{~m}^{-2}$ dia $^{-1}$ após colheita da aveia (Avena sativa L.) cultivada em SPD e, BALOTA et al. (2004), estudando o efeito do tempo de manejo e de diferentes sucessões de culturas, verificaram taxas de mineralização de $0,31,0,13$ e $0,14 \mathrm{~g} \mathrm{~m}^{-2}$ dia $^{-1}$, respectivamente, para as sucessões soja/trigo, milho/trigo e algodão/trigo cultivados em SPD.

$\mathrm{Na}$ figura 4 estão reapresentadas as variações nas taxas liquidas de mineralização (a) e nitrificação (b) durante o período amostrado nos tratamentos sob SPD, com 12 e 22 anos de implantação nas sucessões milho/ trigo e soja/trigo.

Em setembro de 2000, as taxas de mineralização e nitrificação nas áreas com resíduos culturais da aveia foram de $43 \%$ e $50 \%$ superiores nos tratamentos com maior tempo de implantação do SPD.

Com o plantio e adubação do milho (outubro de 2000) foi constatada a maior taxa de nitrificação de todo o período amostrado no tratamento com 22 anos de SPD. Rosolem et al. (2003) verificaram que a aplicação de sulfato de amônio, em solos sob plantio direto, promoveu a nitrificação das formas amoniacais para $\mathrm{N}$-nítrico, contudo os autores discutem a influência da matéria orgânica como condicionador do $\mathrm{pH}$ do solo, uma vez que a aplicação de sulfato de amônia promove 

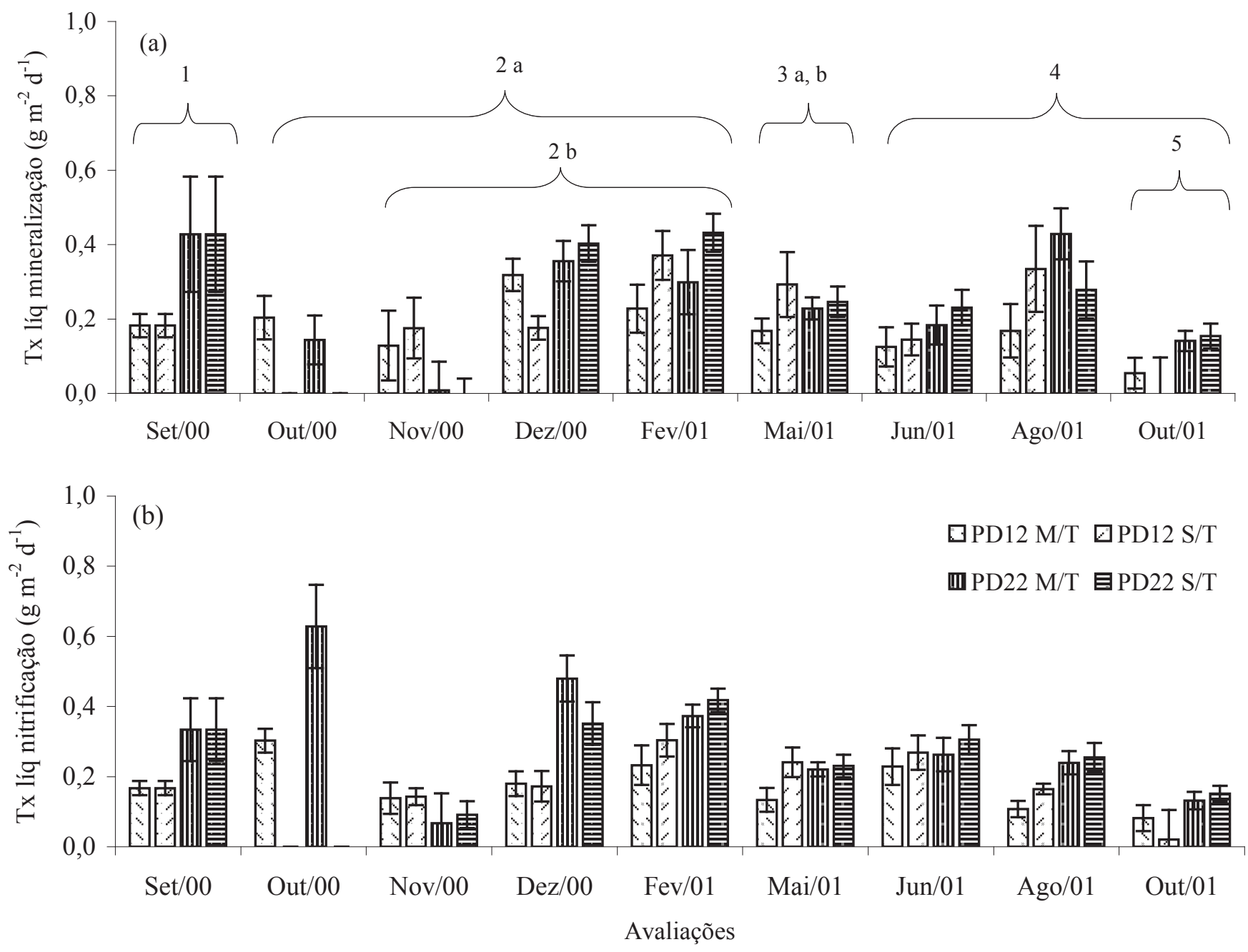

Figura 4. Taxas líquidas de A) mineralização do $\mathrm{N}$ do solo e, B) nitrificação do $\mathrm{N}$ no solo $\left(\mathrm{g} \mathrm{m}^{-2} \mathrm{~d}^{-1}\right)$ para a camada 0,000 - 0,200 $\mathrm{m}$, com 12 e 22 anos sob SPD nas sucessões milho/trigo (M/T) e soja/trigo (S/T), em Tibagi (PR). Os resultados representam a média $(\mathrm{n}=20) \pm$ desvio-padrão. Nota - Os números correspondem à cultura ou resíduo cultural que recobria o solo no período da amostragem: (1) Resíduo de aveia preta; (2) Culturas de Verão em (a) milho e, em (b) soja; (3) Resíduos culturais das culturas de Verão em (a) milho e, em (b) soja; (4) Cultura de Inverno: trigo para todos os tratamentos; (5) Resíduos culturais do trigo, colhido no dia anterior a amostragem das áreas.

rápida acidificação do solo que pode prejudicar a ocorrência da nitrificação (STRONG et al., 1997).

Durante o período em que as áreas permaneceram com as culturas de verão (outubro de 2000 a fevereiro de 2001) as taxas de mineralização e nitrificação não tiveram diferenças significativas para as duas culturas estudadas (milho e soja), com média de $0,23 \mathrm{~g} \mathrm{~m}^{-2} \mathrm{dia}^{-1}$. $O$ valor semelhante da mineralização e nitrificação pode indicar que a transformação predominante no solo seja a passagem das formas amoniacais a formas de N-nítrico, sem que esteja ocorrendo processo de mineralização do N-total da MOS.

Com a proximidade do período de colheita da soja (fevereiro 2001) foram observados aumentos nas taxas de mineralização e nitrificação, o que ocorreu devido ao início da senescência das plantas e, da decomposição das raízes e nódulos no solo (Figura 4a) (YANG e CAI, 2005). Dou et al. (1995), observaram maiores teores de nitrato no solo após o corte das culturas leguminosas de cobertura. LIEBIG et al. (2002) encontraram aumentos na eficiência da ciclagem de nutrientes e no potencial de mineralização do $\mathrm{N}$ no solo para culturas em sucessão a leguminosas.

Em maio de 2001, a sucessão soja/trigo promoveu valores mais elevados nas taxas de mineralização e nitrificação (Figura 4a,b). Neste período, a soja estava em fase de senescência e provavelmente, a menor relação C:N dos resíduos culturais com maior grau de decomponibilidade, pode ter induzido tal comportamento. 
MARQUEZ et al. (2000) constataram a imobilização do fertilizante sulfato de amônio quando aplicado sobre palha de milho no plantio direto, ocorrendo no período subsequente o aumento do N-nitrato no solo. Em experimento de campo realizado nos Campos Gerais no Estado do Paraná, observou-se maior necessidade de utilização de fertilizantes nitrogenados na fase inicial do SPD, devido ao elevado processo de imobilização do $\mathrm{N}$, causado pela retenção do elemento nos resíduos culturais com alta relação C:N (SÁ et al., 2001).

ArelaçãoC:N podeexplicar parcialmentea cinética da mineralização e imobilização do N. Estes processos estão mais relacionados à bioquímica dos resíduos como a solubilidade dos compostos de $\mathrm{C}$ e as quantidades de celulose e lignina. Assim, na decomposição dos resíduos culturais existe o efeito do $\mathrm{N}$ remanescente no solo. No caso da decomposição dos resíduos do milho, a baixa concentração de $\mathrm{N}$ promove a imobilização de $\mathrm{N}$ do solo para que os microrganismos possam promover a mineralização do C (MARY et al., 1996).

No período de junho a outubro de 2001, quando as áreas permaneceram recobertas pelo trigo as taxas de mineralização e nitrificação proporcionaram valores médios diferentes somente para o tempo de implantação do SPD. As médias anotadas foram de 0,14 e 0,23 $\mathrm{g} \mathrm{m}^{-2}$ $\mathrm{dia}^{-1}$, respectivamente para 12 e 22 anos de SPD.

\section{Emissões de óxido nitroso do solo}

As emissões de óxido nitroso foram influencias pela sucessão adotada $(\mathrm{p}<0,05)$ com médias de 0,78 e $0,58 \mathrm{mg} \mathrm{m}^{-2} \mathrm{~d}^{-1}$ de $\mathrm{N}-\mathrm{N}_{2} \mathrm{O}$ nas sucessões milho/ trigo e soja/trigo respectivamente. Porém, as médias das emissões para 12 e 22 anos foram de 0,64 e 0,71 $\mathrm{mg} \mathrm{m}^{-2} \mathrm{~d}^{-1}$ respectivamente, mas não tiveram diferença significativa $(\mathrm{p}<0,05)$ (Tabela 6).

SEHY et al. (2003), em estudo sobre as emissões de $\mathrm{N}_{2} \mathrm{O}$ em solos com diferentes níveis de fertilidade cultivados com milho, constataram emissões médias de $1,2 \mathrm{mg} \mathrm{m}^{-2} \mathrm{~d}^{-1}$ com emissão máxima de $33,6 \mathrm{mg} \mathrm{m}^{-2} \mathrm{~d}^{-1}$ de $\mathrm{N}_{2} \mathrm{O}$ duas semanas após a aplicação de $15 \mathrm{~g} \mathrm{~m}^{-2}$ de $\mathrm{N}$-fertilizante.
Em dezembro de 2000, ou seja, no fim do ciclo das culturas de verão (milho e soja), as emissões de $\mathrm{N}_{2} \mathrm{O}$ foram aproximadamente duas vezes mais elevadas na sucessão milho/trigo em relação à sucessão soja/trigo e, em maio de 2001, após a colheita destas culturas, as emissões foram $40 \%$ maiores nos tratamentos cultivados com o milho. Esse fato foi devido à cultura do milho receber adubação nitrogenada enquanto a cultura da soja supriu suas necessidades com o N-fixado simbioticamente, não disponibilizando $\mathrm{N}$ na forma inorgânica no solo.

Contudo, em maio de 2001, em relação à época de amostragem anterior (dezembro de 2000) a sucessão soja/trigo propiciou aumento de aproximadamente $60 \%$ nas emissões de $\mathrm{N}_{2} \mathrm{O}$. YANG e CAI (2005) verificaram que durante o desenvolvimento da soja não foram observados alterações nas emissões de $\mathrm{N}_{2} \mathrm{O}$ em relação ao solo-controle, contudo após a retirada da parte aérea das plantas (colheita) teve início o processo de decomposição das raízes e nódulos e a mineralização do $\mathrm{N}$, que foram responsáveis por $93 \%$ das emissões acumuladas de $\mathrm{N}_{2} \mathrm{O}$ durante todo o período estudado.

As maiores emissões médias de $\mathrm{N}-\mathrm{N}_{2} \mathrm{O}$ do solo $\left(1,20 \mathrm{mg} \mathrm{m}^{-2} \mathrm{~d}^{-1}\right)$ foram anotadas em junho de 2001, sendo nos tratamentos com 22 anos aproximadamente $15 \%$ mais elevadas que nos tratamentos com 12 anos de SPD. Estes fluxos mais elevados de óxido nitroso, neste período, podem estar relacionados à adubação nitrogenada realizada na cultura do trigo, o que pode estar associado ao maior teor de MOS, à maior diversidade funcional de microrganismos do sistema e a manutenção da umidade no solo durante o ano que favorecem as transformações do N no solo, por processos de nitrificação e desnitrificação (FolletT et al., 2005).

As perdas de nitrogênio do solo devido à emissão de óxido nitroso representaram em média valores entre 0,02 e $0,05 \%$ do N-inorgânico no solo; este valor representa um retrato do momento do período que se realizou a amostragem do solo e dos fluxos deste gás. Em relação às taxas de mineralização, a desnitrificação promoveu valores distintos para as sucessões estudadas,

Tabela 6. Emissões de $\mathrm{N}-\mathrm{N}_{2} \mathrm{O}\left(\mathrm{mg} \mathrm{m}^{-2} \mathrm{~d}^{-1}\right)$ do solo com 12 e 22 de SPD nas sucessões milho/trigo e soja/trigo, em Tibagi (PR)

\begin{tabular}{lcccccc}
\hline Tratamentos & Dez/00 & Mai/01 & Jun/01 & Ago/01 & Out/01 \\
\hline & $0,47 \pm 0,10 \mathrm{~b}$ & $0,80 \pm 0,16 \mathrm{a}$ & $1,16 \pm 0,13$ ns & $0,56 \pm 0,01 \mathrm{a}$ & $0,63 \pm 0,06 \mathrm{~b}$ & $0,73 \pm 0,09 \mathrm{ab}$ \\
PD 12 M/T & $0,18 \pm 0,07 \mathrm{c}$ & $0,48 \pm 0,13 \mathrm{~b}$ & $1,14 \pm 0,06$ & $0,40 \pm 0,09 \mathrm{~b}$ & $0,70 \pm 0,18 \mathrm{ab}$ & $0,56 \pm 0,11 \mathrm{~b}$ \\
PD 12 S/T & $0,71 \pm 0,13 \mathrm{a}$ & $0,74 \pm 0,01 \mathrm{a}$ & $1,26 \pm 0,17$ & $0,53 \pm 0,18 \mathrm{ab}$ & $0,85 \pm 0,11 \mathrm{a}$ & $0,82 \pm 0,12 \mathrm{a}$ \\
PD 22 M/T & $0,23 \pm 0,09 \mathrm{c}$ & $0,47 \pm 0,13 \mathrm{~b}$ & $1,38 \pm 0,16$ & $0,34 \pm 0,10 \mathrm{~b}$ & $0,66 \pm 0,21 \mathrm{~b}$ & $0,61 \pm 0,14 \mathrm{~b}$ \\
PD 22 S/T & &
\end{tabular}

Os valores representam à média $(\mathrm{n}=6) \pm$ erro-padrão. Médias seguidas da mesma letra na coluna não diferem significativamente no teste de Tukey $(\mathrm{p}<0,05)$. 
ou seja, para a sucessão milho / trigo as emissões médias representaram $0,50 \%$ da taxa de mineralização do $\mathrm{N}$, enquanto para a sucessão soja/trigo foi de $0,34 \%$. O mesmo ocorreu para as taxas de nitrificação, as emissões representaram $0,45 \%$ e $0,26 \%$ para as sucessões milho/ trigo e soja / trigo respectivamente.

Os resultados constantes deste estudo corroboram em parte com a literatura, mostrando que a aplicação do $\mathrm{N}$-fertilizante no solo, além de promover reduções nas taxas de mineralização do N (CARPENTERS-BOGGS et al., 2000, MARQueZ et al., 2000) aumentaram a emissão de $\mathrm{N}_{2} \mathrm{O}$ (Dalal et al., 2003; SeHy et al., 2003; WeItZ et al., 2001).

Uma alternativa para diminuir esta perda para o sistema agrícola e o impacto ambiental consiste no uso de sistemas de rotação de culturas que possam envolver culturas fixadoras de $\mathrm{N}$, juntamente com culturas com elevado aporte de resíduos vegetais, e desta forma, promover a elevação da MOS, com acúmulo de C e N no solo, aumentar as taxas de mineralização e reduzir as emissões de $\mathrm{N}_{2} \mathrm{O}$ (AmADO et al ., 2001).

\section{CONCLUSÕES}

1. O tempo de SPD promove aumentos na MOS e consequentemente nas quantidades de $\mathrm{N}$-inorgânico e nas taxas de mineralização e nitrificação do $\mathrm{N}$ no solo, contudo não se observam maiores emissões de óxido nitroso;

2. $\mathrm{O} \mathrm{N}$-fertilizante promove maiores emissões de óxido nitroso no milho e no trigo, para a soja verificase aumento nas emissões após a colheita, devido a decomposição do sistema radicular e dos nódulos fixadores;

3. As maiores perdas de $\mathrm{N}$ na forma de óxido nitroso, em relação às taxas de mineralização, são observadas na sucessãomilho/ trigo. Essefatodemonstra que uma alternativa para reduzir as perdas é o uso de leguminosas no sistema de rotação de culturas.

\section{AGRADECIMENTOS}

Ao Conselho Nacional de Desenvolvimento Científico e Tecnológico (CNPq) pela bolsa de estudo concedida. Aos Srs. Lúcio Miranda, Milton Banisk, Paulo Sérgio, Engenheiro Agrônomo Jorge Dorócio Ferreira e demais funcionários da Fazenda Santa Branca, em Tibagi (PR), pelo apoio logístico na realização deste trabalho.

\section{REFERÊNCIAS}

AMADO, T.J.C.; BAYER, C.; ELTZ, F.L.; BRUM, A.C.R. Potencial de culturas de cobertura em acumular carbono e nitrogênio no solo no plantio direto e a melhoria da qualidade ambiental. Revista Brasileira de Ciência do Solo, v.25, p.189-197, 2001.
BALOTA, E.L.; COLOZZI FILHO, A.; ANDRADE, D.S.; DICK, R.P. Long-term tillage and crop rotation effects on microbial biomass and $\mathrm{C}$ and $\mathrm{N}$ mineralization in a Brazilian Oxisol. Soil \& Tillage Research, v.77, p.137-145, 2004.

BAYER, C.; AMADO, T.J.C.; MIELNICZUK, J.; MARTINNETO, L.; FERNANDES, S.V. Tillage and cropping system effects on organic matter storage in Acrisol soil in southern Brazil. Soil \& Tillage Research, v.54, p.101-109, 2000.

BERNOUX M.; ARROUAYS D.; CERRI C.C.; BOURENNANE $\mathrm{H}$. Modeling vertical distribution of carbon in Oxisols of the Western Brazilian Amazon (Rondônia). Soil Science, v.163, p.941-951. 1998.

BLAKE, G.R.; HARTGE, K.H. Bulk density. In: KLUTE, A. (Ed.). Methods of soil analysis. Pt.1. 2.ed. Madison: ASA, 1986. p. 364-367. (Agronomy, 9)

BOWDEN, R.D.; STEUDLER, P.A.; MELILLO, J.M. Annual nitrous oxide fluxes from temperate forest soil in the northeastern United State. Journal of Geophysical Research, v.95, p.13997-14005, 1990.

BUSTAMANTE, M.M.C.; MARTINELLI, L.A.; SILVA, D.A.; CAMARGO, P.B.; KLINK, C A.; DOMINGUES, T.F.; SANTOS, R.V. ${ }^{15} \mathrm{~N}$ natural abundance in woody plants and soils of central Brazilian Savannas (Cerrado). Ecological Applications, v.14, p.200-213, 2004

CARPENTER-BOGGS, L.; PIKUL JUNIOR, J.; VIGIL, M.F.; RIEDELL, W.E. Soil nitrogen mineralization influenced by crop rotation and nitrogen fertilization. Soil Science Society of American Journal, v.64, p.2038-2045, 2000.

CARVALHO JUNIOR, V.N. Deposição atmosférica e composição química da água de chuva. Revolução Tecnológica, v.25, p.61-71, 2004.

DALAL, R.C.; WANG, W.; ROBERTSON, G.P.; PARTON, W.J. Nitrous oxide emission from Australian agricultural lands and mitigation options: a review. Australian Journal of Soil Research, v.41, p.165-195, 2003.

DENARDIN, J.E.; KOCHHANN, R.A. Requisitos para a implantação e a manutenção do plantio direto. In: CNPTEMBRAPA, FUNDACEP-FETRIGO, FUNDAÇÃO ABC. Plantio direto no Brasil. Passo Fundo: Aldeia Norte, 1993. p.19-27.

DIEKOW, J., MIELNICZUK, J., KNICKER, H., BAYER, C., DICK, D.P., KÖGEL-KNABNER, I. Soil C and N stocks as affected by cropping systems and nitrogen fertilization in a southern Brazil Acrisol managed under no-tillage for 17 year. Soil \& Tillage Research, v.81, p.87-95, 2005.

DOU, Z., FOX, R.H.; TOTH, J.D. Seasonal soil nitrate dynamics in corn as affected by tillage and nitrogen source. Soil Science Society of American Journal, v.59, p.858-864, 1995.

EMBRAPA. Manual de métodos de análise do solo. Rio de Janeiro, 1979. 247p. 
EMBRAPA. Sistema Brasileiro de Classificação de Solos. 2.ed. Rio de Janeiro, 2006. 306p.

FALLEIRO, R.M.; SOUZA, C.M.; SILVA, C.S.W.; SEDIYAMA, C.S.; SILVA, A.A.; FAGUNDES, J.L. Influência dos sistemas de preparo nas propriedades químicas e físicas do solo. Revista Brasileira de Ciência do Solo, v.27, p.1097-1104, 2003.

FOLLETT, R. F.; SHAFER, S. R.; FRANZLUEBBERS, A. J. Research and implementation needs to mitigate greenhouse gas emissions from agriculture in the USA. Soil \& Tillage Research, v.83, p.159-166, 2005.

GLASENER, K.M.; WAGGER, M.G.; MACKOWN, C.T.; VOLK, R.J. Contributions of shoot and roots nitrogen-15 labeled legume nitrogen source to a sequence of three cereal crop. Soil Science Society of American Journal, v.66, p.523530, 2002.

HIRAOKA, E.Y.; VENZKE FILHO, S.P.; SIQUEIRA NETO, M.; PICCOLO, M.C. Quantificação dos resíduos culturais e a concentração de polifenóis em duas sucessões de culturas sob 12 e 22 anos de sistema de plantio direto. In: FERTBIO 2002. Rio de Janeiro, 2002. Anais...Rio de Janeiro: Universidade Federal Rural do Rio de Janeiro, 2002. (CD-ROM)

HURLBERT, S.H. Pseudoreplication and the design of ecological field experiments. Ecological Monographs, v.54, p.187-211, 1984.

IPCC (2001) Technical summary: Climate change 2001. The Scientific Basis. Contributions of Working Group I. of the Intergovernmental Panel on Climate Change. In: J.T. HOUGHTON; Y. DING; J.D. GRIGGS; M. NOUGER; P.J. VAN DER LINDEN; X. DAI; K. MASKELL; C.A. JOHNSON. (Ed.). Cambridge-UK: Cambridge University Press, 2001. 398p.

KRIFT, T.A.J. van der.; BERENDSE, F. The effect of plant species on soil nitrogen mineralization. Journal of Ecology, v.89, p.555-561, 2001.

KRISTENSEN, H.L.; DEBOSZ, K; McCARTY, G.W. Sort-term effects of tillage on mineralization of nitrogen and carbon in soil. Soil Biology \& Biochemistry, v.35, p.979-986, 2003.

KUZYAKOV, Y.; FRIEDEL, J.K.; STAHR, K. Review of mechanisms and quantification of priming effects. Soil Biology \& Biochemistry, v.32, p.1485-1498, 2000.

LARA CABEZAS, W.A.R. Imobilização do nitrogênio na cultura do milho após a aplicação em pré e pós-semeadura da uréia e sulfato de amônio. Revista Plantio Direto, p.14-20, 2001.

LIEBIG, M.A.; VARVEL, G.E.; DORAN, J.W.; WIENHOLD, B.J. Crop sequence and nitrogen fertilization effects on soil properties in the Western Corn Belt. Soil Science Society of American Journal, v.66, p.596-601, 2002.

LOVATO, T., MIELNICZUK, J., BAYER, C., VEZZANI, F. Adições de carbono e nitrogênio e sua relação com os estoques no solo e com o rendimento do milho em sistemas de manejo. Revista Brasileira de Ciência do Solo, v.28, p.175-187, 2004.

MARQUEZ, T.C.L.L.S.M.; VASCONCELLOS, C.A.; PEREIRA FILHO, I.; FRANÇA, G.E.; CRUZ, J.C. Evolvimento de dióxido de carbono e mineralização do nitrogênio em latossolo vermelho-escuro com diferentes manejos. Pesquisa Agropecuária Brasileira, v.30 p.581-589, 2000.

MARY, B.; RECOUS, S.; DARWIS, D.; ROBIN, D. Interactions between decomposition of plant residues and nitrogen cycling in soil. Plant \& Soil, v.181, p.71-82, 1996.

MUNSELL COMPANY INC. Munsell Soil Color Charts. Baltimore, 1954.

PEREZ, K.S.S.; RAMOS, M.L.G.; McMANUS, C. Nitrogênio da biomassa microbiana em solo cultivado com soja, sob diferentes sistemas de manejo, nos Cerrados. Pesquisa Agropecuária Brasileira, v.40, p.137-144, 2005.

PICCOLO, M.C.; NEILL, C.; CERRI, C.C. Net mineralization and net nitrification along a tropical forest-to-pasture chronossequence. Plant \& Soil, v.162, p.61-71, 1994.

PÖTTKER, D.; ROMAN, E.S. Efeitos de resíduos de culturas e do pousio de inverno sobre a resposta do milho a nitrogênio. Pesquisa Agropecuária Brasileira, v.29, p.763-770, 1994.

RAIJ, B. van.; QUAGGIO, J.A.; CANTARELLA, H.; FERREIRA, M.E.; LOPES, A.S.; BATAGLIA, O.C. Análise química do solo para fins de fertilidade. Campinas: Fundação Cargill, 1987. $170 \mathrm{p}$.

REMBON, F.S.; MACKENZIE, A.F. Soybean nitrogen contribution to corn and residual nitrate under conventional tillage and no-till. Canadian Journal of Soil Science, v.77, p.543-551, 1997.

RICE, C.W.; SMITH, M.S. Short-term immobilization of fertilizer nitrogen at the surface of no-till and plowed soils. Soil Science Society of American Journal, v.48, p.295-297, 1984.

ROS, C.O.; SALET, R.L.; PORO, R.L.; MACHADO, J.N.C. Disponibilidade de nitrogênio e produtividade de milho e trigo com diferentes métodos de adubação nitrogenada no sistema plantio direto. Ciência Rural, v.33, p.799-804, 2003.

ROSOLEM, C.A.; FOLONI, J.S.S.; OLIVEIRA, RH. Dinâmica do nitrogênio no solo em razão da calagem e adubação nitrogenada, com palha na superfície. Pesquisa Agropecuária Brasileira, v.38, p.301-309, 2003.

RUZICKA, J.; HANSEN, E.H. Flow injection analysis. New York: Wiley Interscience, 1981. 395p.

SÁ, J.C.M. Dinâmica da matéria do solo em sistemas de manejo convencional e plantio direto. Piracicaba, 2001. 141p. Tese (Doutorado) - Escola Superior de Agricultura "Luiz de Queiroz", Universidade de São Paulo. 
SÁ,J.C.M.; CERRI, C.C.;DICK, W.A.; LAL, R.; VENZKE FILHO, S.P.; PICCOLO, M.C.; FEIGL, B.J. Organic mater dynamics and carbon sequestration rates for a tillage chronosequence in a Brazilian oxisol. Soil Science Society of American Journal, v.65, p.1486-1499, 2001.

SCHLESSINGER, W.H. Biogeochemistry: An analysis of global change. London: Academic Press, 1997. v.1, 588p.

SEHY, U.; RUSER, R.; MUNCH, J.C. Nitrous oxide fluxes from maize fields: relationship to yield, site-specific fertilization, and soil conditions. Agriculture, Ecosystems and Environment, v.99, p.97-111, 2003.

SIERRA, J.; MARBÁN, L. Nitrogen mineralization pattern of an oxisol of Guadeloupe, French West Indies. Soil Science Society of American Journal, v.64, p.2002-2010, 2000.

SISTI, C.J.; SANTOS, H.P.; KOHHANN, R.; ALVES, B.J.R.; URQUIAGA, S.; BODDEY, R.M. Change in carbon and nitrogen stocks in soil under 13 years of conventional or zero tillage in southern Brazil. Soil \& Tillage Research, v.76, p.3958, 2004.

SOLORZANO, L. Determination of ammonia in natural waters by the phenol hypoclorite method. Limnology and Oceanography, v.14, p.799-801, 1969.

STRONG, D.T.; SALE, P.W.G.; HELYAR, K.R. Initial soil pH affects the $\mathrm{pH}$ at which nitrification ceases due to self-induced acidification of microbial microsites. Australian Journal of Soil Research, v.35, p.565-570, 1997.
THOMSEN, I.K.; OLESEN, J.E.; SCHJØNNING, P.; JENSEN, B.; CHRISTENSEN, B.T. Net mineralization of soil $\mathrm{N}$ and ${ }^{15} \mathrm{~N}$-ryegrass residue in differently textured soils of similar mineralogical composition. Soil Biology \& Biochemistry, v.33, p.277-285, 2000.

TORMENA, C.A.; FRIEDRICH, R.; PINTRO, J.C.; COSTA, A.C.S.;FIDALSKI, J. Propriedades físicas e taxa deestratificação de carbono orgânico num latossolo vermelho após dez anos sob dois sistemas de manejo. Revista Brasileira de Ciência do Solo, v.28, p.1023-1031, 2004.

TOUCHTON, J.T.; HARGROVE, W.L. Nitrogen sources and methods of application for no-tillage corn production. Agronomy Journal, v.74, p.823-826, 1982.

TRINSOUTROT, I.; RECOUS, S.; BENTZ, B.; LINÈRES, M.; CHÈNEBY, D.; NICOLARDOT, B. Biochemical quality of crop residues and carbon and nitrogen mineralization kinetic under nonlimiting nitrogen conditions. Soil Science Society of American Journal, v.64, p.918-926, 2000.

WEITZ, A.M.; LINDER, E.; FROLKING, S.; CRILL, P.M; KELLER, M. $\mathrm{N}_{2} \mathrm{O}$ emissions from humid tropical agricultural soils: effects of soil moisture, texture and nitrogen availability. Soil Biology \& Biochemistry, v.33, p.1077-1093, 2001.

WHIETHÖLTER, S. Nitrogênio no solo sob plantio direto. Revista Plantio Direto, p.38-42, 2000.

YANG, L.; CAI, Z. The effect of growing soybean (Glicine max. L.) on $\mathrm{N}_{2} \mathrm{O}$ emission from soil. Soil Biology \& Biochemistry, v.37, p.1205-1209, 2005. 